TITLE:

\title{
Occurrence of Epitokes of Platynereis bicanaliculata (Baird) (Annelida : Polychaeta) in Koajiro Bay, Miura Peninsula, Central Japan
}

\author{
$\operatorname{AUTHOR}(\mathrm{S})$ : \\ Fukao, Ryuzo
}

\section{CITATION:}

Fukao, Ryuzo. Occurrence of Epitokes of Platynereis bicanaliculata (Baird) (Annelida: Polychaeta) in Koajiro Bay, Miura Peninsula, Central Japan. PUBLICATIONS OF THE SETO MARINE BIOLOGICAL LABORATORY 1996, 37(3-6): 227-237

ISSUE DATE:

1996-12-25

URL:

http://hdl.handle.net/2433/176266

RIGHT: 


\title{
Occurrence of Epitokes of Platynereis bicanaliculata (Baird) (Annelida: Polychaeta) in Koajiro Bay, Miura Peninsula, Central Japan
}

\author{
RYUZO FUKAO \\ National Research Institute of Fisheries Science, \\ 6-31-1 Nagai, Yokosuka, Kanagawa 238-03, Japan
}

\begin{abstract}
The occurrence of epitokes of Platynereis bicanaliculata was examined in an eelgrass bed in Koajiro Bay, Miura Peninsula, central Japan, using a fish lamp to establish a convenient and reliable sampling design for environmental studies. The epitokes occurred in the period from late February to mid-November. The peak of epitokal swarming activity was in warm season, but its time in the season differed among years, i.e. late June in 1992 and early April in 1993, presumably, depending on weather conditions. The synchronous epitokal swarming was evidenced, superficially as asymmetrically semi-lunar with the major concentration of activity around a few days after full moon. The difference in the periodicity from the Californian forms exhibiting swarming activity around new moon is postulated to be attributable to populational genetic difference, if it is not due to the artificial induction of swarming by using a fish lamp in the present form. In either case, an annual relative density of the present species which may be an useful indicator of the environmental quality of coastal waters including eelgrass beds can be given by the samplings of epitokes using a fish lamp in the evening a few days after full moon and new moon in the warmer months from March to September.
\end{abstract}

Key words: Platynereis bicanaliculata, epitokal swarming, semi-lunar periodicity, indicator, sampling design

\section{Introduction}

The metamorphosis of the immature polychaete worm into a special reproductive form is known as epitoky or epigamy. Many species of Errantia polychaetes exhibit epitokal breeding swarming, a surprising number of worms migrating to the surface of the sea for spawning (Clark, 1961). Polychaetes are an important component of coastal water ecosystems and regarded as one of the key taxa for marine environmental quality monitoring (Pocklington \& Wells, 1992). Providing that the mechanisms or the accurate periodicity is clarified, epitokal breeding swarms may be convenient for the monitoring, primarily because the sufficient quantity of matured worms for the study could be collected in a short period of time (Fukao, 1995a).

Platynereis bicanaliculata (Nereidae) is known to form epitokal breeding swarms (Blake, 1975; Fong, 1993; Imajima, 1980; Rickett et al., 1985; Roe, 1975). It is widely distributed in coastal waters of the Pacific; Japan (north to Hokkaido and south to Okinawa), Taiwan, Australia, Hawaii, and western coast of North America (Blake, 1975; Imajima, 1980). In the Japanese waters, it inhabits soft bottoms including eelgrass beds, ranging from intertidal zones to depths of $30 \mathrm{~m}$ (Imajima, 1980; Kikuchi, 1974). It may have a considerable tolerance to pollution, since it often occurs together with well-established indicator species of organic pollution (or eutrophication), such as Capitella capitata (Fabricius) and Paraprionospio sp., in heavily polluted waters of embayment (Kitamori, 1966; Yokoyama, 1985).

In the eelgrass beds of Koajiro Bay on Miura Peninsula, central Japan, a number of individuals of Platynereis bicanaliculata were collected during the survey on organotin pollution conducted in the summer of 1990 (Fukao, 1995a, b). Numerous epitokes gathered 
around a fish lamp in one night (June 25, 2 days after new moon) but only a few did another night (July 20, 2 days before new moon), suggesting the synchronous epitokal swarming presumably controlled by lunar periodicity as is known for the Californian forms (Blake, 1975; Fong, 1993; Ricketts et al., 1985; Roe, 1975). The present study was planned to clarify the occurrence of epitokes of $P$. bicanaliculata.

\section{Study Area and Methods}

Koajiro Bay $\left(139^{\circ} 37^{\prime} \mathrm{E}, 35^{\circ} 09^{\prime} \mathrm{N}\right)$ is a small, shallow, narrowly penetrated arm of the sea of Sagami Bay on Miura Peninsula near its tip (Fig. 1). A small stream, Uranokawa River, flows into the bay at its innermost end, and an intertidal mud flat develops around the mouth of the stream. An eelgrass bed near the intertidal mud flat was selected for sampling and observation. The bed covers a bottom area of ca. $3000 \mathrm{~m}^{2}$, in depths ranging from ca. 0.5 to $2.0 \mathrm{~m}$ at low water of spring tides, where the maximum tidal amplitude is about $2 \mathrm{~m}$, and receives the inflow from a small rivulet on the middle of its shallower boundary. The substratum of the bed changes gradually from soft mud to sandy mud offshore.

A preliminary sampling was made on April 21, 1992, 2 days after full moon, and resulted in abundant catch of epitokes, that suggested periodical epitokal swarming. Based on this result, samplings were conducted using a submersible fish lamp (500 watt) at intervals of nearly two weeks, in the evening of 2 to 6 days after full and new moon, from May 6, 1992 to May 10, 1993. In each evening, lighting started about 15 minutes after sunset and lasted for 2 hours. The epitokes gathering

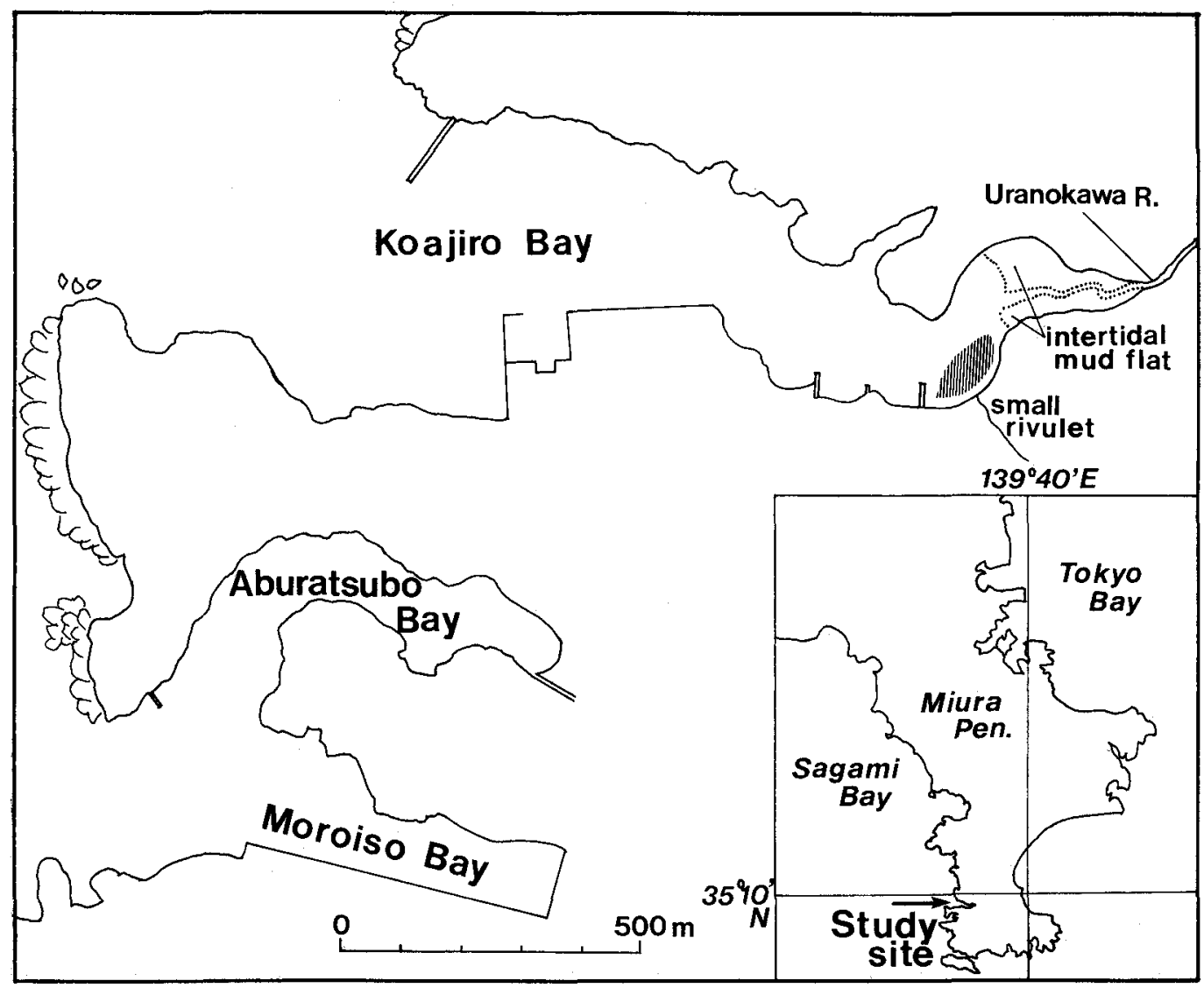

Fig. 1. Study area. Shadowed area shows the eelgrass bed where samplings were made. 
around the lamp were collected by a dip net; they were anesthetized in $\mathrm{MgCl}_{2}$ solution isotonic to sea water and were kept separately in a jar for each successive period of 30 minutes. The epitokes collected were then brought back to the laboratory, were counted, and were fixed in $5 \%$ formalin. Vertical hauls using a net (mouth area of $19 \times 29 \mathrm{~cm}^{2}, 50 \mathrm{~cm}$ long, with $106 \mu \mathrm{m}$ mesh), which were conducted primarily to collect zooplankton, were taken from a depth of $1 \mathrm{~m}$ to the sea surface in the brightly lit waters successively at 15 minutes before the commencement of lighting, and 5 min., 10 min., $15 \mathrm{~min} ., 30 \mathrm{~min} ., 1 \mathrm{~h}, 1.5 \mathrm{~h}$ and $2 \mathrm{~h}$ after the commencement (usually 5 hauls at each time). The epitokes in the plankton samples collected were counted and their numbers per $\mathrm{m}^{3}$ of water were calibrated.

Supplementary samplings were made using the submersible fish lamp and the dip net at nearly weekly intervals from July 8 of August $6,1993$.

\section{Results}

The relationship between the number of worms collected during a period of 30 minutes by a dip net and the mean of calibrated numbers of worms per $\mathrm{m}^{3}$ of water from the catches

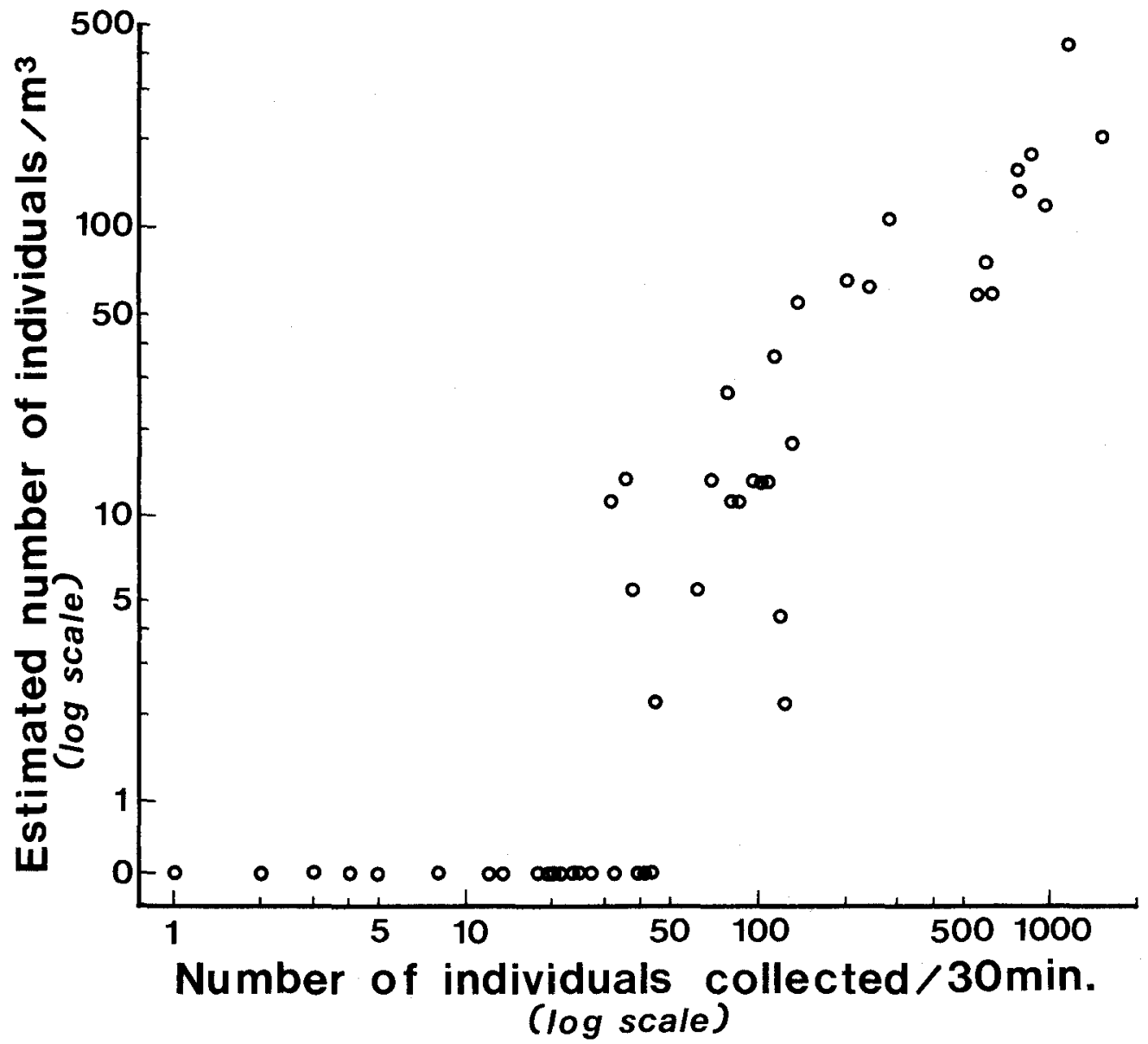

Fig. 2. Relationship between the number of worms collected by a dip net during a 30 minute period and the mean value of the estimated numbers of worms per $\mathrm{m}^{3}$ derived from the vertical hauls at the beginning and the end of the 30 minute period. 
in the hauls at the beginning ( 5 min. after in initial 30 minutes period; always no worms were observed and collected) and the end of the same period is shown in Fig. 2. When only less than 30 worms were collected by a dip net in the 30 minute period, the worms were never caught in the hauls both at the beginning and at the end of the period.

It was actually impossible to collect all the worms emerged in the light of a fish lamp. Large and dense swarms were too abundant to be completely collected by a dip net. When the worms emerged scatterlingly or sporadically, on the other hand, some disappeared soon in the dark before being netted with a rapid swimming in a beeline across the light. As the worms increase in the light, they are apt to stay longer within the light with running madly about around the lamp and gradually form a large and dense swarm, which looks like a column of swarming mosquitos. Spawning behavior, the male approaches a floating female with peristaltic movement and spirals around her, which results in forming a spawning aggregation with a female and a few to several males, and a release of gametes which looks like a drop of milk dispersing in the water were observed in swarms, especially in large and dense ones. There might be hit or miss in the vertical hauls. Clogging of the net in the hauls by varying amount of plankters would deteriorate the efficiency of collecting the swiftly moving worms. The worms attracted to the lamp, especially after a swarm was formed, might be exposed for predation by fish and other carnivores. The factors affecting the obtained two indices of relative abundance of the worms are variously involved. Nevertheless, as read from Fig. 2, these two values show a good correlation; the regression line computed is $\mathrm{Y}=0.195 \mathrm{X}-2.679(\mathrm{r}=0.833, \mathrm{t}=14.339$, d.f. $56, \mathrm{p}<0.001)$, where $\mathrm{X}$ is the number of worms collected by the dip net and $Y$ the number of worms per $\mathrm{m}^{3}$ of water calibrated from the catches in the hauls (the cases that no worms were collected in the 30 minute period were excluded from the calculation). Thus, the collection by a dip net is assumed to give a good representation of the relative abundance of worms gathering around the fish lamp in the present study.

Seasonal changes in the number of epitokous worms collected are shown in Fig. 3. The epitokes occurred as early in late February and as late in mid-November. The maximal number was recorded in July in 1992 and in April in 1993. The surface water temperature showed abrupt fall in November 1992 from $18.4^{\circ} \mathrm{C}$ in mid-November to $13.5^{\circ} \mathrm{C}$ in late November, and continuing rise in February 1993 from the lowest $11.3^{\circ} \mathrm{C}$ in January.

In 1992, the number of worms collected in the night of a few days after full moon was always greater than those of a few days after the preceding and the following new moon. The fluctuation pattern in the number of worms recorded on days after full moon was followed by that after new moon with a time lag of about two weeks, though the amplitude of the latter was much smaller than that of the former. The number after full moon increased gradually to the peak on July 20 (2512 individuals), and that after new moon on August 3 (250 individuals). Thereafter, both the numbers decreased rather abruptly, except for the period between October 2 and November 13.

In 1993, the epitokes were first collected on February 25. The number of worms collected increased successively and its peak was attained on April 9 (2114 individuals), 2 days after full moon. The number recorded on April 26, 4 days after new moon, was markedly smaller than those on a few days after the preceding and the following full moon, as was observed in 1992. The number of worms collected on March 26 was greater than that on a day after preceding full moon, but was much smaller than that on a day after the following full moon. Similarly to the fluctuation pattern in the number of worms collected in 1992, the numbers recorded on days after new and full moon were nearly parallel to each other with a time lag of about two weeks. The fluctuation in the former preceded that in the latter, however, being reversed to those in 1992. The former increased abruptly from 2 on Feb. 25 to 302 on March 26 and then was reduced to 135 on Apr. 26. The latter increased abruptly from 72 on Mar. 11 to the 


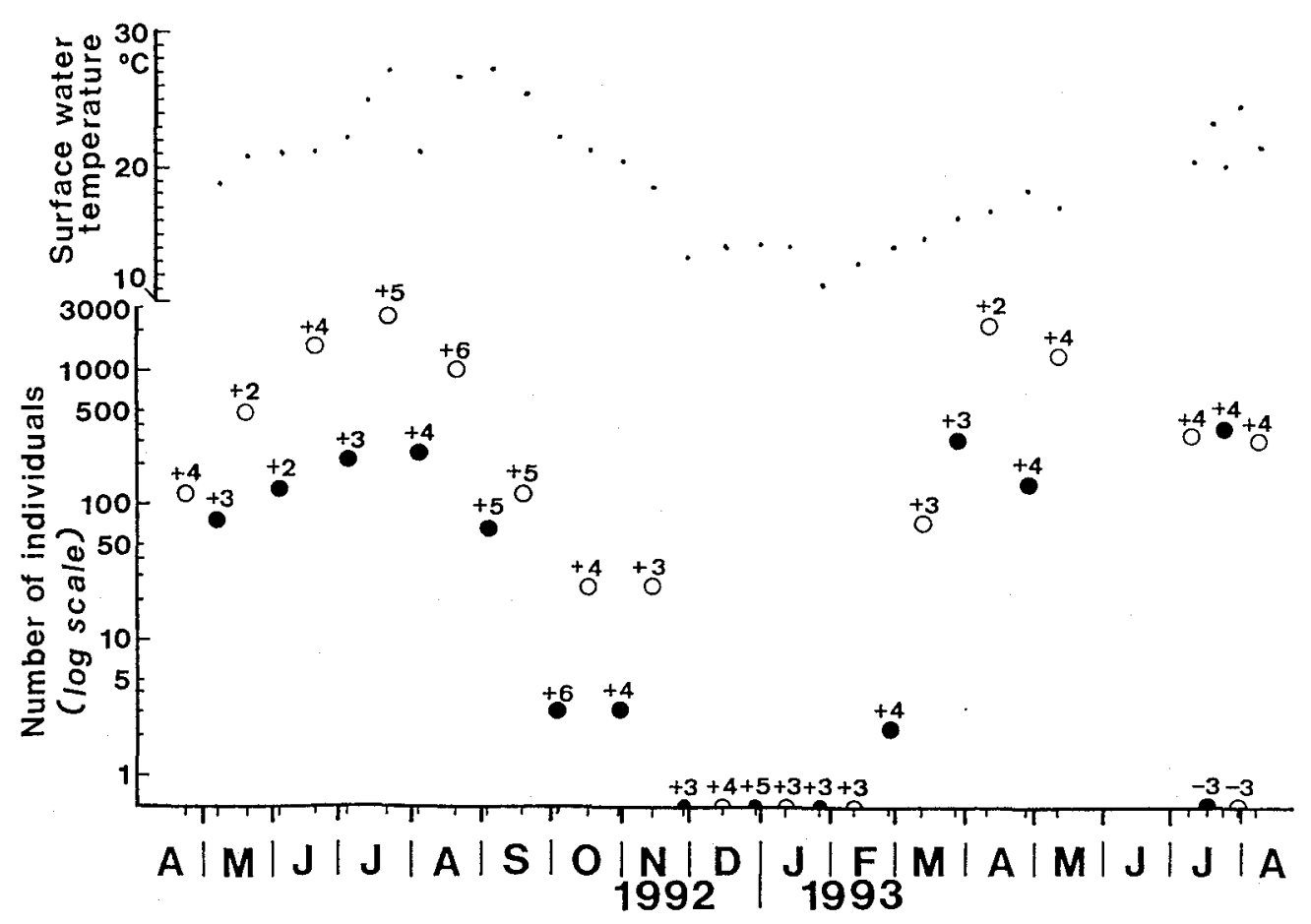

Fig. 3. Seasonal changes in the number of worms collected during 2 hour sampling period. Numerals with plus or minus sign above marks show the number of days after or before full moon (for open circles) or new moon (solid circles). The change in surface water temperature is also shown at top.

observed peak of 2114 on Apr. 9 and then was reduced to 1260 on May 10. The supplementary survey was set for July and early in August, 1993 in conformity with the peak of swarming activity in the preceding year of 1992 . While the number recorded on July 23 ( 350 individuals) was the highest for days after new moon, those on days after the preceding and the following full moon were unexpectedly much smaller than the numbers in the peak on July 20 in the previous year and in the peak on April 9 of the year. The latter two were nearly equal (322 individuals on July 8 and 310 individuals on August 6) and slightly smaller than the former. The above might be contrary to the parallel fluctuation pattern between the numbers of worms collected on days after new and full moon observed theretofore.

The supplementary survey with weekly sampling suggests the semi-lunar epitokal swarming activity of the worms. In the samplings on 3 days before both new and full moon, on July 16 and July 30 , no worms could be collected, though the brief emergence of a worm swimming quickly in a beeline across the light was observed only twice on July 16, 3 days before new moon.

The numbers of worms collected and the estimated densities from the hauls are shown separately for each period of 30 minutes on each sampling day in Fig. 4. The first worm emerged in the light of the fish lamp 15 (June 19, 1992) to 70 (February 25, 1993) minutes after the commencement of lighting, mostly between 25 and 40 minutes. Generally, the first worm disappeared soon in the dark before netting with a rapid swim in a beeline. Consequently, no worms were collected in most of the initial period of sampling. In most cases, the number of worms gathered increased through the second 30 minute period, attained the peak in the third, but decreased during the fourth, and sometimes worms emerged only sporadically and 
briefly at the end of 2 hours sampling. The largest catch was obtained in the third 30 minute period in 15 out of 21 cases in which the worms were collected. From May 6 to August 3, 1992, throughout, the largest number of worms collected was recorded in the third period, followed by the last, the second and the initial.

In both 1992 and 1993, the catch of worms in the last 30 minute period on the day of the epitokal swarming peak approximated to the greatest of the third period. On August 19 and September 2, 1992, and April 26, 1993, after the peak of epitokal swarming in each year, the greatest catch was obtained in the last 30 minute period. In these cases, the epitokal
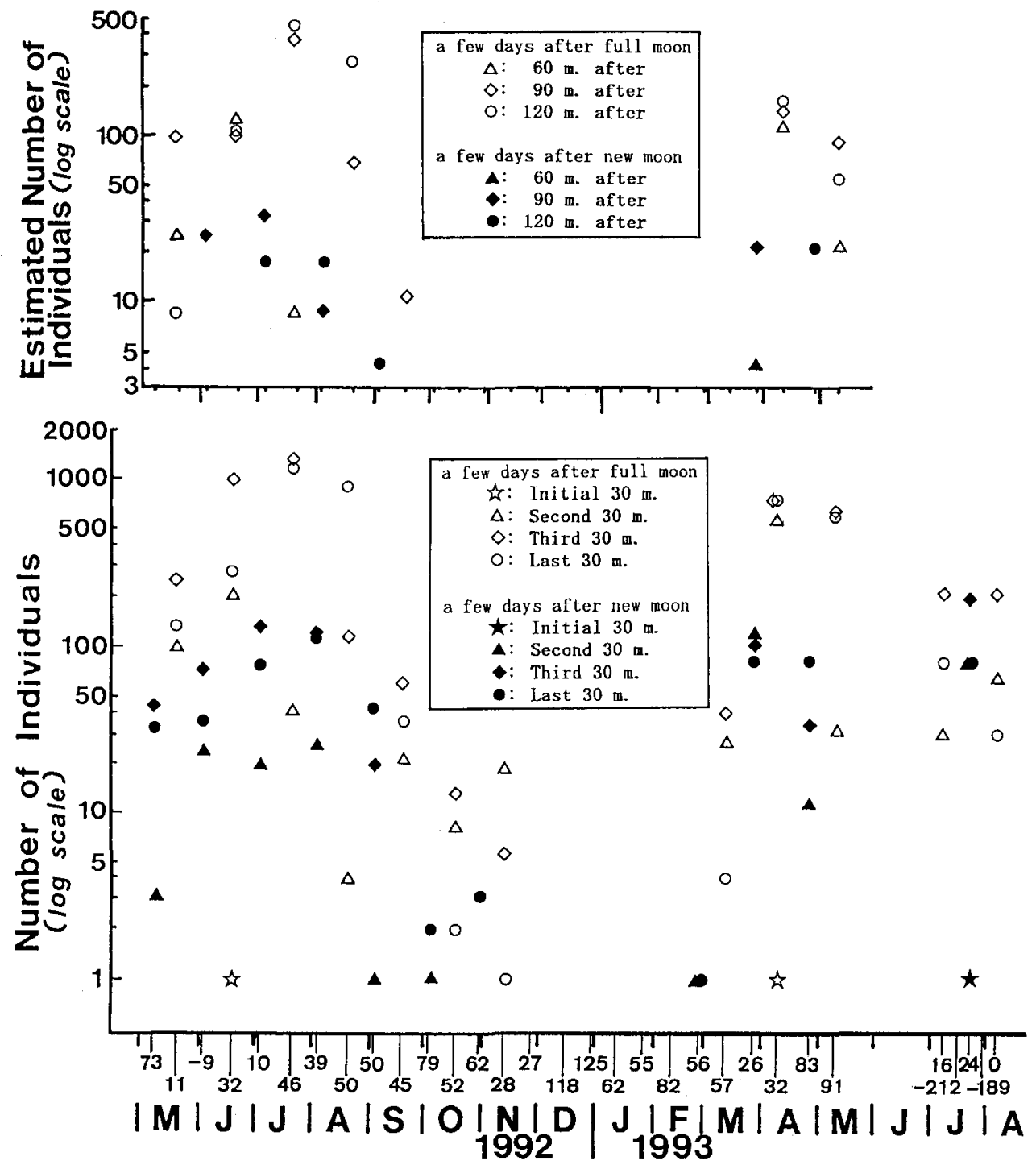

Fig. 4. The numbers of worms collected in each of four 30 minute periods of 2 hour sampling period on each sampling day (bottom). The estimated numbers of worms $/ \mathrm{m}^{3}$ derived from the vertical hauls at the end of $2 \mathrm{nd}, 3 \mathrm{rd}$ and last 30 minute period are shown above. Numerals below the abscissa show the time of the nearest high tide from the commencement of the sampling; expressed as minutes after or before (with minus sign) the commencement. 
swarming was still near the climax of the day at the end of the 2 hours sampling. On the other hand, the largest number of worms collected was in the second period on November 13 , 1992, and March 26 and August 6, 1993.

Variations in the pattern were irrespective of the tide, so far as the time of the high tide varied from 9 minutes before to 91 minutes after the commencement of sampling (Fig. 4).

\section{Discussion}

The present study appears to show superficially that the overall pattern of epitokal swarming activity (i.e. spawning activity) of $P$. bicanaliculata in Koajiro Bay is asymmetrically semi-lunar, with major concentration of activity around a few days after full moon. The Californian form, on the contrary, has been known to have spawning activity around new moon (Blake, 1975; Ricketts et al., 1985; Fong, 1993). Fong (1993) reported the presence of small swarming peaks around the period of ambient full moon in his laboratory experiment, suggesting a possible semi-lunar component to the overt swarming rhythm. The present results seem to be just the reverse to the Fong's observation in the relative height between the peaks around full moon and new moon. The following two inferences are drawn for this discrepancy.

One is that the worms in Koajiro Bay may be genetically different from the Californian form of $P$. bicanaliculata (different species or geographical races with different endogenous rhythm). Another concerns the sampling design including the use of a fish lamp. The environmental cue for epitokal metamorphosis of the Californian form has been contended to be the full moon or the gradual decline of moonlight from full moon to last quarter moon (Blake, 1975; Fong, 1993). In either case, ripe worms completed metamorphosis must have appeared in the bottom by a few days after full moon. Epitokal swarming observed a few days after full moon in the present study could be inferred to be induced artificially by a fish lamp earlier than naturally started by a sign connected with the endogenous rhythm. In the present study, no worm was collected a few days before new moon. In the nights around new moon in summer months in California, the higher high water occurs as in spring tide at mid-night when epitokal swarming has been observed (Roe, 1975; Ricketts et al., 1985). On the Pacific coast of Japan, this tidal pattern occurs a few to several days before new moon as in neap tide. New moon has no night high tide, but one early in the morning and one toward the evening. A few days after new and full moon, high tide occurs just after sunset and sunrise as in spring tide. Sampling of the worms around high water a few to several days before new moon would be necessary in order to elucidate the mechanism of lunar swarming periodicity of the present species in Japanese waters.

In Japanese waters, epitokal breeding swarms of the present species have been known to occur during the period from April to June (Imajima, 1980). The present study revealed that the Koajiro population is much more reproductively eurythermal with a spawning season from late February to mid-November (surface water temperature ranging from 14.0 to $27.1^{\circ}$ C). The peak of spawning activity was believed to be annually variable within warmer months. Some Platynereis species have been known to have a certain measure of annual variation in the reproductive season due to the annual difference in weather, e.g. mild winter vs. hard winter (Rasmussen, 1973). The marked difference in the peak of epitokal swarming of the present species between the years of 1992 and 1993 could also be attributed to the annual difference in weather.

Three factors of the weather around the study period are shown in Fig. 5 (according to the Yokohama District Meteorological Observatory, data from the Misaki Meteorological station). They may be influential in the reproductive cycles of benthic animals, primarily being concerned with the water temperature of the shallow estuaries like the present study 

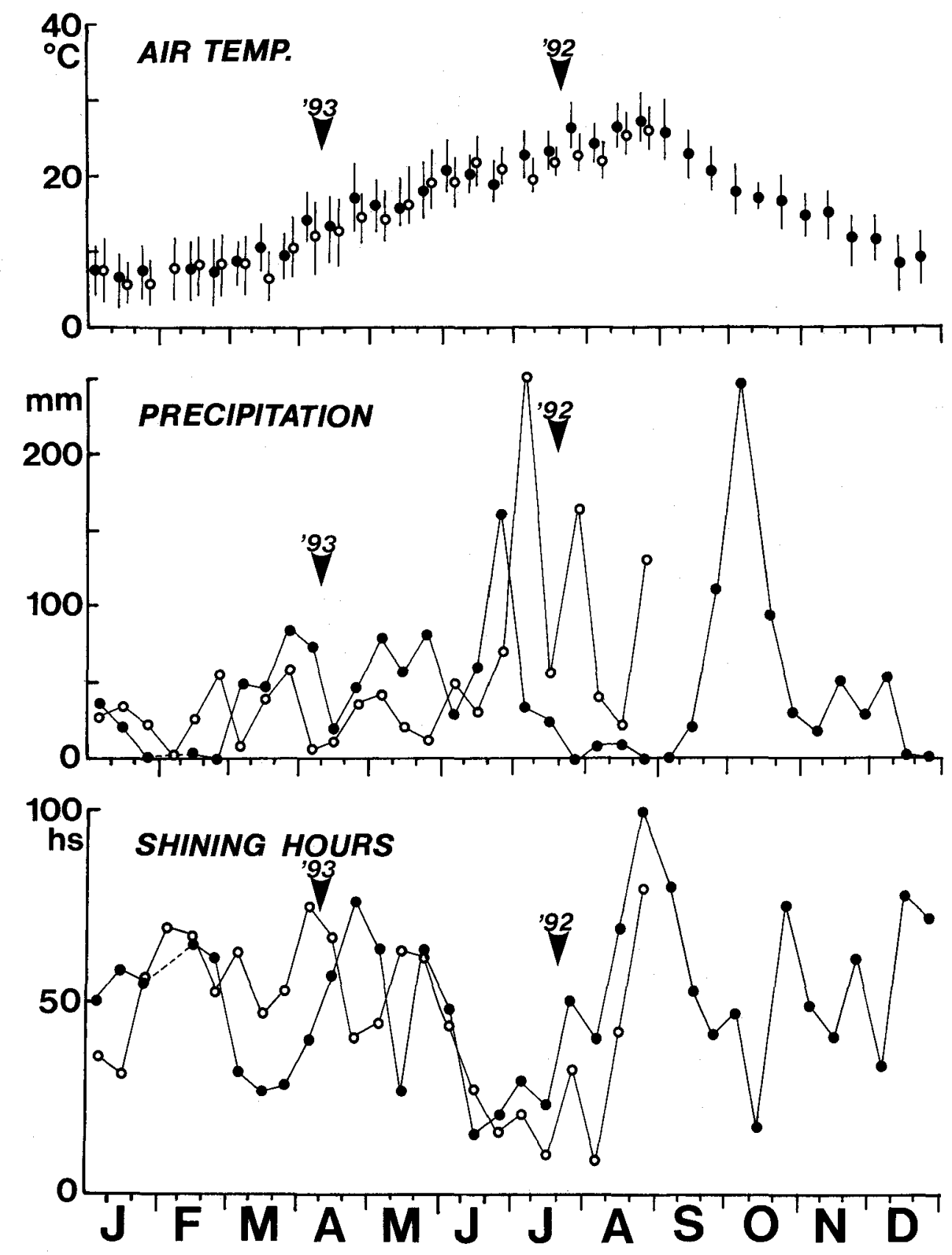

Fig. 5. Air temperature, precipitation and shining hours in the district of the study area (according to the Yokohama District Meteorological Observatory, data from the Misaki Meteorological Station). Solid circles for 1992; open circles for 1993. Arrowheads with " 92 " and " 93 " show the peak of epitokal swarming in 1992 and 1993 respectively. 
area. The cyclic variation in sea temperature is frequently suggested to be the principal annual component of environment which drives the various processes of gametogenesis and any accompanying somatic changes in marine invertebrates including nereid polychaetes (Olive \& Garwood, 1983). Obviously, shining hours in March were more frequent in 1993 than in 1992. Precipitation in March was less in 1993 than in 1992. Although the air temperatures in March were not necessarily higher in 1993 than in 1992, the above might lead to the earlier maturation and epitokal metamorphosis of the worms in 1993. The unusual pattern observed in March 1993, that the number of worms collected a few days after full moon (March 11) was smaller than that a few days after the following new moon (March 26), may reflect the sharp emergence of matured individuals in this year.

The number of worms collected in three sampling occasions during the supplementary survey in July and early August, 1993, is somewhat perplexing, being contrary to the parallel fluctuation pattern between the numbers recorded on days after full and new moon observed theretofore. The unexpectedly fewer worms collected on days after full moon during the survey might be also caused by the earlier maturation; the number of potential epitokes may decrease earlier as both sexes of this annual species die after spawning in swarms (Roe, 1975; Olive \& Garwood, 1983). In addition to this, air temperature was unusually low during this period. The period had also less shining hours and much more precipitation than that the same season in 1992. Precipitation also appears to be a plausible cause of the unusual pattern; the number of worms collected a few days after new moon was larger than those collected a few days after the preceding and the following full moon during the supplementary survey. A heavy rain (amounted to $167 \mathrm{~mm} /$ day) and an additional rain $(32 \mathrm{~mm} /$ day) visited the district of the study area 3 days and one day before the sampling on July 8, 1993, 4 days after full moon. At the sampling, a small rivulet which flows into the shallows in front of the eelgrass bed of the sampling site changed into a rapid stream with more than $1 \mathrm{~m}$ wide and more than $30 \mathrm{~cm}$ deep from the usual delicate stream with less than $30 \mathrm{~cm}$ wide and less than $5 \mathrm{~cm}$ deep. The successive flow of the cooler fresh water fed by the stream and Uranokawa River which flows into the adjacent mud flat through the primeval forest (Fig. 1) must have dominated the bed much more than usual, especially during low tide and affected the metamorphosis of the worms. At the sampling made on July 23, the rivulet was approximate to the usual delicate stream. Some worms which were expected to emerge if no heavy rain had visited might fail to metamorphose into epitokes until 4 days after full moon of July 4 and emerged late as epitokes on July 23, 4 days after subsequent new moon. The delayed epitokes as an addition may possibly lead to the highest number collected in the sampling of July 23 among the samplings made a few days after new moon in the present study.

A comparable heavy rain $(165 \mathrm{~mm} /$ day) had once visited the district on Oct. 8, 1992 with additional rain of 2 to $33 \mathrm{~mm} /$ day, totaling $48 \mathrm{~mm}$, visited during the 4 days from Oct. 12 to 15. The worms collected in the sampling on October 16, 1992, 4 days after full moon, yielded rather small catch of worms (23 individuals) that was approximated by the catch one month later (24 individuals) (Fig. 3). The numbers of worms collected a few days after the preceding and the following new moon were the same ( 3 individuals). These deflections in the decreasing trend in the number of epitokes emerged toward the end of reproductive season in 1992 might be also explained by the delayed metamorphosis in some of worms.

The annual relative density of the present species may be an useful indicator of the area including eelgrass beds studied. Since $P$. bicanaliculata is an annual and semelpalous nereid, the relative density of the year must be able to obtain from the adequate sampling of epitokes of the species. Epitokal swarms occurred in the light of a fish lamp may be artificially induced ones, but still the epitokes are no doubt produced from the local worm population. The samplings using a fish lamp immediately after the sunset as in the present study is convenient for researchers. The overall pattern in the emergency of epitokes in the warmer 
months showed the striking contrast between the years of 1992 and 1993. In 1992, the number of worms recorded was gradually increased to the peak attained in late July and early in August, and then decreased rather abruptly. In 1993, on the other hand, it was abruptly increased to the peak attained in late March and early in April, and then was plausible to decrease gently, with a special peak on July 23 for days after new moon. It could be safely said that the peak of swarming activity can not occur from October to February, since worms of a number of two figures or less was recorded at most during the period in the present study. The numbers of worms recorded on days after full moon were much larger than those after new moon in the usual parallel fluctuation pattern between them. A relative density of $P$. bicanaliculata can usually be drawn by the samplings of epitokes using a fish lamp conducted in the evening a few days after full moon in warmer months from March to September. However, the unusual pattern observed in the supplementary survey suggests that the samplings on days after new moon are also desirable, especially in the area received a flow of fresh water. The smaller number recorded on days after new moon in the usual pattern may also serve as the rather sensitive measure than the larger number on days after full moon on a certain occasion, hence both the numbers advisable. Samplings were made for two hours from 15 minutes after sunset in the present study. An extended sampling should be needed in the midst of spawning season, however, as dense swarms were observed at the end of the samplings of 2 hours. Lastly, consecutive collections each night from full moon to new moon in the midst of spawning season will naturally give more detailed picture of epitokal emergence and swarming, hence the more accurate measure.

\section{Acknowledgments}

The Koajiro Fishermen's Cooperative Association provided the facilities for my field study. I express my thanks to Dr. Hisashi Yokoyama of the National Research Institute of Aquaculture for the identification of Platynereis bicanaliculata.

\section{References}

Blake, J.A. 1975. The larval development of polychaeta from the northern California coast. III. Eighteen species of Errantia. Ophelia, 14: 23-84.

Clark, R.B. 1961. The origin and formation of the heteronereis. Biol. Rev., 36: 199-236.

Fong, P.P. 1993. Lunar control of epitokal swarming in the polychaete Platynereis bicanaliculata (Baird) from central California. Bull. Mar. Sci., 52: 911-924.

Fukao, R. 1995a. The summer invertebrate fauna in and around the eelgrass beds in Koajiro Bay and Moroiso Bay, Miura Peninsula, central Japan. Physiol. Ecol. Japan, 31: 21-38.

Fukao, R. 1995b. Organotins in the organisms collected in and around the eelgrass beds of Koajiro Bay and Moroiso Bay, Miura Peninsula, in the summer of 1990. Physiol. Ecol. Japan, 31: 39-57.

Imajima, M. 1980. Systematics and ecology of the Japanese polychaetes-(4). (2) Systematics of the family Nereidae-2. Aquabiology, 2: 436-439. [in Japanese]

Kitamori, R. 1966. Biological judgment of water pollution in the marine environment. Bull. Water Treat. Tech., 7:1-7. [in Japanese]

Olive, P.J. \& Garwood, P.R. 1983. The importance of long term endogenous rhythms in the maintenance of reproductive cycles of marine invertebrates: a reappraisal. Internat. J. Inv. Reproduc., 6: 339-347.

Pocklington, P. \& Wells, P.G. 1992. Polychaetes key taxa for marine environmental quality monitoring. Mar. Pollut. Bull., 24: 593-598.

Rasmussen, E. 1973. Systematics and ecology of the Isefjord marine fauna (Denmark) with a survey of the eelgrass (Zostera) vegetation and its communities. Ophelia, 11: 1-507.

Ricketts, E., Calvin, J., Hedgpeth, J.W. \& Phillips, D.W. 1985. Between Pacific Tides. Stanford University Press, Stanford. 652 pp. 
Roe, P. 1975. Aspects of life history and of territorial behavior in young individuals of Platynereis bicanaliculata and Nereis vexillosa (Annelida, Polychaeta). Pacific Sci., 29: 341-348.

Yokoyama, H. 1985. Relationships between organic pollution and macrobenthos in coastal waters. Seikatsu Eisei, 29: 301-311. [in Japanese] 